\title{
Negotiating Cultural Identities in Diaspora: A Conceptual Review of Third Space
}

\begin{abstract}
In association with different disciplines, the conceptualization of the third space with different jargons and theoretical tropes has evolved historically. However, this article makes a brief review about the concept of the third space in relation with formation of human subjectivities. Particularly, the ideas of Arnold Van Gennep, Victor Turner, Edward Burghardt DuBois, Gloria Anzaldua and Homi Bhabha are reviewed briefly. In fact, observing the cultural rituals and how they transform human subjectivities, Gennep locates the transitory space which is crucial informing changing roles and identities of human beings. From cultural rituals, Turner takes up this idea in the process of social changes. He identifies this space in between the interaction of structured and anti structured social roles. Likewise, DuBois expands this idea in examining subjectivities of Black people. But, Anzaldua incorporates all people and formation of their identities in her analysis. Multiple factors and allegiances are responsible in forming human identities in her concept. Similarly, Bhabha concentrates in colonial and post colonial context and analyzes how the cultural interactions of colonized and colonizer deconstruct the bipolar concept of cultural identities and give birth of a new form of identities in the hybrid space of cultural interaction. Bhabha's conceptualization is relevant in conceptualizing immigrants' cultural identities in diaspora.
\end{abstract}

Keywords: ambivalence, cultural identities, double consciousness, inbetweenness, mestiza, third space, diaspora, hybridity

\section{Introduction}

The conceptualization of the third space deconstructs the bipolar notion about the formation of human subjectivity. Rather, it assumes that the human subjectivity emerges from the inbetween space of these polarities. However, theorists vary in their conceptualizations of the third space in different social, cultural and political contexts. The transitory liminality and third space has been taken up by Arnold Van Gennep, Victor Turner, William Edward Burghardt Du-Bois and Gloria Anzaldua in various ways to explain development of human subjectivity. They take references of cultural ritual, social changes, double consciousness, and pluralities of self in their conceptualizations. Similarly, Homi Bhabha further substantiates his conceptualization of the third space in the political discourse of hybridity,

* Mr. Nagendra is Lecturer in English at T.U. 
ambivalence, in-betweenness with references to colonial context. This is also pertinent in understanding cultural identities of immigrants living in the trans-border geo-cultural space of diaspora.

\section{Third Space and Human Subjectivities}

Human participation in cultural ritual plays vital role in the formation of cultural identity and subjectivity. Such rituals symbolize transformation of social status of the person. Gennep (1960) analyzes the transitory in-between space of cultural rituals in Les Rites de Passage. His analysis of rituals consists of three parts; rites of separation, rites of transition and rites of adoption. In rites of separation, the person undergoing the ritual is stripped off the social status he or she has possessed. Then the person undergoes various ritual practices in the second liminal period of social status which is known as transitional phase. After undergoing the transitional phase, the person finally adopts new cultural and social role. Gennep remarks that the transitional second stage is crucial in shaping and preparing the person to adopt a new social status.

Gennep (1960) shows a special interest in the transitional phase. He compares the phase with the territorial no man's land between two countries. In this zone, a person finds in a special situation as neither law of the adjoining countries applies. The person wavers between two worlds. Like this territorial passage, non-territorial transitions also consist of a moment or period of uncertainty in the liminal stage. This is an unstable and uncertain social and religious position. During the transition state a person remains uncertain as he or she has been separated from a clearly defined state in the past and has not been incorporated yet into a clearly defined future state.

Beyond personal level, Turner (1969) expands Gennep's concept of liminality of studying rituals to social change also. He concentrates on the processes of social change, both from the point of view of the individual experience and the development of common beliefs that characterize the social group. In The Ritual Process (1969), Turner explicates that human social life is shaped by the interplay of structured social roles and the blurring of social roles (i.e., anti-structure) which occurs in the ritual context. Structured roles provide the continuity and anti-structured roles affirm the importance of discontinuity of social practices. They are linked dialectically. Turner elucidates that human beings require time and separation from their social obligations to process and adjust to change. He finds antistructured roles an essential feature of human existence because it is through the operation of anti-structure that human beings gain an understanding of their humanity and spirituality.

Such transitory liminal space has been used to theorize Afro-American subjectivity by Du Bois (1903). With references to the historical injustice to the black people in America, he conceptualizes double-consciousness in The Souls of Black Folk. It refers to a source of 
inward "twoness" generally experienced by African-Americans because of their racialized oppression and discrimination in a white-dominated society. Du Bois asserts that African Americans are forced to view themselves from the negative perspectives of the outside society.

Du Bois (1903) elaborates that blacks are born with "a veil, and gifted with second-sight in this American world - a world which yields him no true self consciousness, but only lets him see himself through the revelation of the other world" (p. 215). Such imposed vision of looking own self renders double consciousness. For him, it is in a sense "of looking at one's self through the eyes of others, of measuring one's soul by the tape of a world that looks on in amused contempt and pity" ( p. 215). Having one's own sense of self and also having imposed contempt for an ascribed self is what he calls double consciousness. It renders in African American "two souls, two thoughts, two unreconciled strivings; two warring ideals in one dark body, whose dogged strength alone keeps it from being torn asunder" (Du Bois, 1903, p. 215). Their self image is in perpetual conflictual negotiation.

Du Bois explicates that having two antagonistic identities leads to negotiation and enduring conflicts between self image of a person and the imposed view of outsider. Consequently, the person struggles to live with the misrepresentations of the outside world. Instead of antagonism between one's own sense of self and imposed contempt, DuBois is suggesting a merging of positive meanings of blackness and Africaness. He wrote extensively and in detail about the positive meanings of blackness in terms of Africa's early civilizations and their contributions as leaders in world history.

Instead of double consciousness of the specific group in specific historical context, Anzaldua (1987) postulates that multiple factors are responsible in formation of individual self and subjectivity. Her Borderlands/La Frontera (1987) exemplifies that identity is constructed across difference. She stresses for the necessity of a new politics of difference to accompany this new sense of self. Borderlands maps a sense of the plurality of self, which Anzaldua calls mestiza or border consciousness. This consciousness emerges from a subjectivity structured by multiple determinants i.e. gender, class, sexuality in competing cultures and racial identities.

Anzaldua theorizes this consciousness as a constant shifting process or activity of breaking down binary dualism. It creates the third space, the in-between, border, or interstice that allows contradictions to co-exist in the production of the new element. She emphasizes to the consciousness that emerges from the awareness of multiple subjectivities. This contributes to the development of a new paradigm for the theorizing differences. The differences are not mutually exclusive. Rather they co-exist at once rendering multiple subjectivities. The simultaneous existence of differences and opposites has been conceptualized by Bhabha in his concept of hybridity, ambivalence and third space in colonial and post colonial context. 


\section{Bhabha and The Beyond}

Bhabha (1994) conceptualizes coloniality and postcoloniality in political discourse of hybridity, mimicry, liminality, in-betweenness and third space. These concepts go beyond the polarity of the self and the other, and the East and the West. Rather they envision a liminal and interstitial space where multiple cultures interact rendering ambivalence. In fact, he asserts that culture does not exist in isolation, rather interact and overlap within a hybrid space. He calls this space as the third space of enunciation.

Bhabha explains that our existence today is living on the borderlines of the present. The shifting condition is often characterized using prefix 'post' as in; "postmodernism, postcolonialism, postfeminsm" (Bhabha, 1994, p. 1). In these jargons the 'post' does not indicate the sequentiality. Rather, it indicates the: "restless and revisionary energy" (Bhabha, 1994, p. 4) that changes: "the present into an expanded and ex-centric site of experience and empowerment"( Bhabha, 1994, p. 4). Bhabha asserts that such transformation leads us to beyond. The beyond is neither a new horizon, nor a leaving behind of the past. In the beyond: "we find ourselves in the moment of transit where space and time cross to produce complex figures of difference and identity, past and present, inside and outside, inclusion and exclusion" (Bhabha, 1994, p. 1). Thus, the beyond signifies: "spatial distance, marks progress, promises the future" (Bhabha, 1994, p. 4) that opens the new possibilities and potentialities.

The beyond is unknowable, and unrepresentable. There is no return to present solely which is the process of repetition. As a result, it becomes disjunctive and displaced. And there is a sense of; "disorientation, disturbance of direction, in the beyond" (Bhabha, 1994, p. 1). However, being in the beyond is to live in an intervening space. It allows returning to present to redefine existing cultural practices, restate historic commonality and to touch the future. In this sense the 'beyond' is a space of intervention. The intervention enacts upon cultural differences redefining human subjectivities.

\section{In-Between Space}

The subjectivities and the articulation of cultural difference are important for Bhabha. The articulation of cultural differences, for Bhabha, is in- between spaces. These in-between spaces provide; "the terrain for elaborating strategies of selfhood - singular or communal that initiate new sings of identity and innovative sites of collaboration, and contestation, in the act of defining the idea of society itself" (Bhabha, 1994, p.1-2). This is the place where the crossing over of time and cultural differences occurs and where new signs of identity are formed. The pre-existing cultural codes and ethnic traits get redefined in this space. The cultural differences are shaped by tradition but they are negotiated and redefined through the conditions of contingency and contradictions. 
The cultural differences interact and negotiate leading to transformation that creates new and fresh. Bhabha asserts that the cultural interaction of in-between space creates newness that is not part of the past and the present. It creates a sense of the new as a revolutionary act of cultural translation. Bhabha (1994) clarifies:

Such act does not merely recall the past as social cause or aesthetic precedent; it renews the past, refiguring it as a contingent 'in-between' space, that innovates and interrupts the performance of the present. The past- present becomes part of necessity, not the nostalgia, of living. (7)

Thus, Bhabha (1994) does not negate the role of past and present. They play crucial rules in forming cultural identity negotiating in-between cultural space. In fact, in- between space is not simply merging between two opposites. But it should be understood as confusion between two opposites and stands between oppositions at once.

Being creative, fertile and unstable, the in-between space renders the confusion. Bhabha's in-between might be defined as:

The creative, malleable indeterminacy involving feelings of simultaneously repulsion and desire that exist at the interface between self and other, or between the polarities of unequal world that we still inhabit, of what Bhabha calls the 'ongoing colonial present'. (Boehmer, 2005, p. 355)

Bhabha regards such phenomenon as one of the legacies of colonial discourse that is still operative in cotemporary global culture. Consequently, they produce hybrid cultural identities.

\section{Hybridity}

In post-colonial discussion the term hybridity is used to represent the transcultural form resulting from the encounter of colonizer and colonized culture. Bhabha conceptualizes hybridity to describe the construction of culture and identity within conditions of colonial antagonism and inequity. It arises out of the culturally internalized interaction between colonizers and colonized. He argues that colonizers and colonized are mutually dependent in constructing a shared culture. So, the hybridity is the product of the interdependence and mutual construction of the subjectivity of colonizer and colonized. Bhabha explains that such hybridity celebrates multiplicities and pluralities of identity and rejects the notions of essentialist views of identity.

Bhabha acknowledges the plurality of voices and subjectivities in hybrid space. He develops his notion of hybridity "from Mikhail Bakhtin, who uses it to discriminate texts with a 
'single voice' (lyrical poems) from those with a 'double voice' (such as novels, whose narratorcites characters speaking in their own voice - these texts are hybridic)"(Easthoe, 1998, p. 343). Moreover, Bhabha borrows Jacques Derrida's deconstructive strategies to destabilize the colonial fixity and binary opposition. Bhabha's hybridity is Derridean difference applied to colonialist texts. It is the product of difference and postponement both. In this sense, he questions the dominant meaning of dominant culture by referring to hybridity and difference.

Bhabha deconstructs the colonial project of essentialzing and stereotyping the colonized as a perpetual other. For Bhabha, hybridity is the process by which the colonial governing authority undertakes to translate the identity of the colonized (the Other) within a singular universal framework. However, it fails in doing so. Rather, it produces something familiar but new. Bhabha asserts that a new hybrid identity or subject-position emerges from the interweaving of elements of the colonizer and colonized. It discards the validity and authenticity of any essentialist cultural identity.

Bhabha goes back to Franz Fanon (1963) to suggest that liminality and hybridity are necessary attributes of the colonial condition. For Fanon psychic trauma results when the colonized subject realizes that he can never attain the whiteness he has been taught to desire or shed the darkness he has learnt to devalue. Bhabha amplifies this to suggest that colonial identities are always a matter of flux and agony. It is always in a relation to the place of other that colonial desire is articulated. Fanon's image of black skin and white masks is not, Bhabha explains, a neat division but "a doubling, dissembling image of being in at least two places at once which makes it impossible for the devalued, insatiable evolve (an abandonment neurotic, Fanon's claim)to accept the colonizer invitation to identity"(as cited in Loomba, 2006, p. 148). The negotiations in between two spaces deconstruct colonial division of the self and other.

The image black skin/white masks, for Bhabha evokes an ambivalence that indicates not just the trauma of the colonial subjects but also the working of colonial authority as well as the dynamics of resistance. Colonial authority undermines itself by not being able to replicate its own self perfectly. In "Signs Taken for Wonders", he discusses the transmission of The Bible in colonial India. The book is hybridized in the process of being communicated to the natives. He further explicates; "hybridity is a problematic of colonial representation and individuation that reverses the effects of the colonialist disavowal, so that other "denied" knowledge enter upon the dominant discourse and estrange the basis of its authority- its rules of recognition" (Bhabha, 1994, p. 114). Hybridity, thus, is an intrusion of the denied other into the dominant colonial discourse.

Hybridity goes beyond any national or cultural polarization and, thus, brings forth the advantage of being in in-between space. Bhabha's hybridity is formed within the situation 
of colonial enmity and inequality, and he actually emphasizes this inequality and uncanny cultural difference. This liminal position is empowered enough to challenge the authenticity and authority of the dominant discourse. Bhabha believes that hybridity; "is the revaluation of the assumption of colonial identity which manifests the necessary deformation and displacement of all sites of discrimination and domination" (Bhabha, 1994, p.159). In this sense, it is a form of resistance of the colonized.

Hybridity in this sense should not be misunderstood as a simple amalgamation of the two cultures and practices. It does not simply signify an essential dialectic of colonizer/ colonized. Such a simplification neglects the inequalities of power and the very basis of human interaction. On the contrary, Bhabha argues that all social collectives, nation states, cultures or small-scale ethnic groups, are caught in a continuous process of hybridity. They all have developed in relation to a larger context and therefore consist of elements of different origins which they, to varying extent, have in common. For him, hybridity goes beyond any binary operation and direct cultural domination and oppression.

The cultural contact can thus never be reduced to a clash between totalities based on, for example, culture, race, ethnicity or religion. Rather, it is constituted by a series of encounters between individuals and groups in different social circumstances. One of the most interesting aspects of Bhabha's reasoning is the prospect of encounters. Such encounters actually result in something new and substantially different from just mixture of the two. This creative possibility of hybrid space undermines straight forward domination to the minority and marginalized cultures by the powerful one.

Bhabha has shifted this subversion of authority through hybridization. For Bhabha, hybridity discredits colonial authority over the sole grip on meaning. Rather, it validates other culture and language to have traces on meaning. So, Bhabha defines it as; "a problematic of colonial representation...that reverses the effects of the colonialist disavowal, so that other "denied" knowledge enters upon the dominant discourse and estrange the basis of its authority" (Bhabha, 1994, p. 156). The hybridity of colonial discourse thus reverses the structures of domination in the colonial situation. It describes a process in which the single voice of colonial authority undermines the operation of colonial power. In doing so, it inscribes and discloses the trace of the other so that it reveals itself as double-voiced.

On the whole, Bhabha claims that colonial cultures are hybrid. Cultures are not detached and isolated. They should be regarded as temporal phenomena which are affected by each other. Therefore, a cultural contact is not a historical happening in a distinct point of time; rather, it involves a continuous series of contacts that has already begun and continues to affect the relationship between cultures. A particular origin cannot be referred to. Through the passage of time, some roots might be eradicated or changed. In a hybrid context, essentialist claims to a pure history or origin would not be tenable. Rather, they are in 
constant process of negotiation and interaction. The interaction and negotiation is; "Third Space of Enunciation" (34) for Bhabha (1994).

\section{The Third Space}

Bhabha's third space refers to cultural encounters in contradictory and ambivalent spaces. Cultural identities are negotiated and questioned in this space. Bhabha (1994) sees the third space as the potential location and starting-point:

It is that Third Space, though unrepresentable in itself, which constitutes the discursive conditions of enunciation that ensure that the meaning and symbols of culture have no primordial unity or fixity; that even the same signs can be appropriated, translated, rehistoricized and read anew. (p. 37)

Cultural meanings and sings are reviewed, revised and reread with new perspectives and prospects. Thus, the third space represents both cultural negotiation and transformation, and a general condition of language.

By relating with the general condition of language, Bhabha emphasizes on difference in the conceptualization of the third space. The third space is something like the idea of deferral in Post structuralism. Ferdinand de Saussure suggests that signs acquire meaning through their difference from other signs and thus a culture may be identified by its difference from other cultures. Jacques Derrida suggests that the 'difference' is also 'deferred', a duality that he defined in a new term 'différance'. The third space can be compared to this space of differ and defer. Thus, a culture's difference is never simple and static but ambivalent, changing, and always open to further possible interpretation. Cultural meanings and identities always contain the traces of other meanings and identities in this space.

This third space makes meaning an ambivalent process not a fixed reference. Third space in itself is not representable; it is not an actual space; but it is caused by the openness of sign and symbols and culture that can be appropriated, translated, rehistoricized, and read anew. It is a space of hybridity in and between cultural differences. In E. M. Forster's A Passage to India (1924), the hegemonic English discourse makes a sense of the confusing and traumatic sound in the cave by fixing Aziz in the stereotypical of the sexually uncontrollable other. But Adela re-opens the mystery of the cave by acknowledging that she does not know what happened. A new meaning can be assigned to it and the Indian population turns it into a discourse of victory and possible change. So, there is constant negotiation reappropriation of meaning in the third space. 
Cultural identity always emerges in this fluid, contradictory and ambivalent third space. There is no purity and hierarchy of cultures in this space. For Bhabha (1994), this undermines the exoticism of multiculturalism and celebrates hybridity.

It is significant that the productive capacities of this Third Space have a colonial or postcolonial provenance. For a willingness to descend into that alien territory... may open the way to conceptualizing an international culture, based not on the exoticism of multiculturalism or the diversity of cultures, but on the inscription and articulation of culture's hybridity. (p.198-99)

As a result, cultural identity is constructed in the contradictory and ambivalent space of enunciation. This third space of enunciation is, therefore; "the precondition for the articulation of cultural difference" (p.56). This space; "the cutting edge of translation and negotiation - that carries the burden of the meaning of culture" (p.56).

To understand the liminality of third space, Bhabha uses the metaphor of a staircase. $\mathrm{He}$ cites an example of a house with several floors that are joined by a staircase. A house may consist of several floors that are accessible by a staircase. In order to move from the first to the second floor or vice versa, one needs to use the stairs. The staircase is, thus, metaphorically speaking transcending 'certain binary oppositions' such as high and low by offering a liminal space and a pathway between the extremes. Bhabha regards the liminal space of the staircase as an interstitial passage that allows a social subject to move in and out of different racial subject positions.

The third space is a mode of articulation of different subject positions. It is not reflective but productive space that opens up new possibility. It is, in Bhabha's (1994) postulation, an "interruptive, interrogative, and enunciative" (p. 54) space. It allows the production of new forms of cultural meaning blurring the limitations of existing boundaries. It questions established categorizations of culture and identity. According to Bhabha, this hybrid third space is an ambivalent site where cultural meaning and representation have no "primordial unity or fixity"(p.54). . Such concept challenges our sense of the historical identity of culture as "homogenizing, unifying force, authenticated by originary past, kept alive in the national tradition of the People" (p.54).

The importance of the third space is not to be able to trace two original moments from which the third emerges; rather third space enables other positions to emerge. Displacing the histories, third space initiates new possibilities that demand new and fresh perspectives to understand it. As Bhabha (1994) explains: "the transformational value of [third space] lies in the rearticulation, or translation, of elements that are neither the One...nor the Other... but something else besides, which contests the terms and territories of both" (p.28). The 
third space is part of both other spaces and yet new. It detaches temporarily from alreadyexisting parameters and allows examining them with newer eyes.

Eleanor Byrne (2009) explicates that Bhabha's third space "is not simply one thing or the other, nor both at the same time, but a kind of negotiation between both positions" (p. 42). Karin Ikas and Gerhard Wagner believe that this negotiation is a disseminatory site and leads to a sort of displacement of both groups from their origins. This concept might be labeled as an anti-essentialist subversive strategy against every form of authoritative oppression and monotony. In this sense, this intervening space can be depicted as the "being in the beyond" (Bhabha, 1994, p. 10).

Gilles Deleuze and Felix Guattari's (1987) concept of rhizomatic cartography helps understand the third space theory. Rhizomes grow from multiple points in multiple directions simultaneously on a tree. Rhizomes constantly shift and change, growing simultaneously in all directions. Rather than a tree, with a central knowledge concept from which other knowledge branches off, rhizomes produce knowledge at multiple points and can jump to new points at any time. This rhizome metaphor matches with third space theory. It emphasizes that there are multiple points of power in any given interaction rather than a single power entity that controls everything. Moreover, the multiplicities of power centers open the possibility of multilateral directions of possible extensions.

Third space is fundamentally open. It implies that meaning can be transferred in all kind of directions, not only in between the colonial and colonized and native and host country but between many different enunciatory positions and meanings. But this doesn't mean that everything become meshed in a hybrid space. Bhabha (1994) is concerned to show how culture is a contested location; an ambivalent place that is open for complex and often agonizing negotiations. He wants to bypass simplistic interaction theory by pointing out the complexity of an encounter. The third space of enunciation is employed as a metaphor for the ambiguous virtual field that emerges when two or more individuals or cultures interact. In a sense, the third space is the space of hybridity itself.

\section{Conclusion}

The notion of pluralities, multiplicities and hybridities of the third space substantiates the diasporic cultural identities. The immigrants constantly vacillate between the cultures of their home and host country. They are not free from their shared cultural values and historical experiences on native culture and country. Beware of their 'being', in Stuart Hall's (1994) term, the first-generation immigrants try to perpetuate the native cultural practices and partially let the host culture to intrude in their life. However, the second-generation is not as passionate as the first generation in following native culture. They are also exposed with native cultural practices by their parents at home. At the same, both generations cannot 
resist the encroachment of cultural practices of host country in their life. However, the second generation is relatively more prone in adopting cultural practices of host country. Both generations are negotiating in hybrid space of diaspora which is 'becoming' in Hall's term. Both 'being' and 'becoming' concurrently contribute in the formation of their cultural identities.

Both the first and the second-generations are in the third space. They are in constant process of negotiation and interaction of host and native cultures rendering hybridity in their life. Consequently, immigrants' identities are unstable, agonized and in constant flux vacillating on the both sides of the divide. This undermines the claims of unified self. Besides, their identities may bear traces of the culture of origin and host country. Locating the traces of origin in retrospection is not sufficient in conceptualizing their identities. These traces are rehistoricied and reappropriated in new context. In fact, they equally belong to the past, present and the future. Moreover, they are in constant processes of formation reformation. So, their evolving cultural identities are in the third space of cultural negotiation and transformation.

\section{References}

Anzaldua G. (1987). Borderlands/ La Frontera: The New Mestiza. San Francisco: Aunt Lute.

Bakhtin, M. (1981). The Dialogic Imagination: Four Essays (M. Hoiquist \& C. Emersion, Trans.). Austin: University of Texas Press.

Bhabha, H. K. (1994). The Location of Culture. London: Routledge.

Boehmer, E. (2005).Colonial and Postcolonial Literature: Migrant Metaphors. Oxford: OUP.

Byrne, E. (2009). Homi K. Bhabha. New York: Palgrave.

Deleuze, G. \& Felix G. (1987). A Thousand Plateaus: Capitalism and Schizophrenia. Mankato: University of Minnesota Press.

Derrida, J. (1976). Of Grammatology (G. C. Spivak, Trans.). Baltimore: John Hopkins UP.

Du Bois, W. E. B. (1903). The Souls of Black Folk. New York: Dover Publications.

Easthope, A. (1998). Bhabha, Hybridity and Identity. Textual Practice, 12, 341-348. https:// doi.org 10.1080/09502369808582321.

Fanon, F. (1963). The Wretched of the Earth (R. Philocox, Trans.). New Yrok: Grove .

Forster, E. M. (1924). A Passage to India. Harmondsworth: Penguin.

Gennep, A. V. (1960). The Rites of Passage. Chicago: University of Chicago Press. 
Hall, S. (1994). Cultural Identity and Diaspora. In P. Williams, \& L. Chrisman (Eds.). Colonial Discourse and Post colonial Theory: A Reader (pp.22-44 ). New York: Columbia UP.

Ikas, K. \& Wagner, G. (Eds.). (2009). Communicating in the Third Space. London: Rutledge.

Loomba, A. (2006). Colonialism/Postcolonialiam. London: Routledge.

Turner, V. (1969). The Ritual Process: Structure and Anti-structure. New York: Aldine. 